\title{
Anticancer activities against cholangiocarcinoma, toxicity and pharmacological activities of Thai medicinal plants in animal models
}

Tullayakorn Plengsuriyakarn', Vithoon Viyanant', Veerachai Eursitthichai', Porntipa Picha², Piengchai Kupradinun², Arunporn Itharat $^{3}$ and Kesara Na-Bangchang ${ }^{1,4^{*}}$

\begin{abstract}
Background: Chemotherapy of cholangiocarcinoma (CCA), a devastating cancer with increasing worldwide incidence and mortality rates, is largely ineffective. The discovery and development of effective chemotherapeutics is urgently needed.
\end{abstract}

Methods/Design: The study aimed at evaluating anticancer activities, toxicity, and pharmacological activities of the curcumin compound (CUR), the crude ethanolic extracts of rhizomes of Zingiber officinale Roscoe (Ginger: ZO) and Atractylodes lancea thung. DC (Khod-Kha-Mao: AL), fruits of Piper chaba Hunt. (De-Plee: PC), and Pra-Sa-Prao-Yhai formulation (a mixture of parts of 18 Thai medicinal plants: PPF) were investigated in animal models. Anticholangiocarcinoma (anti-CCA) was assessed using CCA-xenograft nude mouse model. The antihypertensive, analgesic, anti-inflammatory, antipyretic, and anti-ulcer activities and effects on motor coordination were investigated using Rota-rod test, CODA tail-cuff system, writhing and hot plate tests, carrageenan-induced paw edema test, brewer's yeast test, and alcohol-induced gastric ulcer test, respectively. Acute and subacute toxicity tests were performed according to the OECD guideline for testing of chemicals with modification.

Results: Promising anticancer activity against CCA in nude mouse xenograft model was shown for the ethanolic extract of AL at all oral dose levels (1000, 3000, and $5000 \mathrm{mg} / \mathrm{kg}$ body weight) as well as the extracts of ZO, PPF, and CUR compound at the highest dose level (5000, 4000, and $5000 \mathrm{mg} / \mathrm{kg}$ body weight, respectively). PC produced no significant anti-CCA activity. Results from acute and subacute toxicity tests both in mice and rats indicate safety profiles of all the test materials in a broad range of dose levels. No significant toxicity except stomach irritation and general CNS depressant signs were observed. Investigation of pharmacological activities of the test materials revealed promising anti-inflammatory (ZO, PPF, and AL), analgesic (CUR and PPF), antipyretic (CUR and $\mathrm{AL}$ ), antihypertensive (ZO and $\mathrm{AL}$ ), and anti-ulcer (CUR, ZO, and $\mathrm{AL}$ ) activities.

Conclusion: Plants used in Thai traditional medicine for the treatment of various ailments may provide reservoirs of promising candidate chemotherapeutics for the treatment of CCA.

Keywords: Cholangiocarcinoma, Anticancer, Thai medicinal plants, Nude mouse xenograft model

\section{Background}

Cholangiocarcinoma (CCA) is a devastating cancer with increasing worldwide incidence and mortality rate. It is an important public health problem in several parts of Southeast Asia, particularly in the northeastern region

\footnotetext{
* Correspondence: kesaratmu@yahoo.com

'Thailand Center of Excellence for Drug Discovery and Development

(TCEDDD), Thammasat University, Pathumthani, Thailand

Full list of author information is available at the end of the article
}

of Thailand. The major cause of CCA in Thailand is the consumption of improperly cooked and fermented fresh water cyprinoids fish called "Pla-ra" or "Pla-som", which contains Opisthorchis viverrini (OV) and nitrosamine. Lack of effective diagnostic tool and chemotherapeutics are the major constraints for controlling this type of cancer. Chemotherapy of CCA is largely ineffective and clinical efficacy of the standard treatment with 5-fluorouracil (5-FU) is low. Furthermore, the resistance of

\section{Ciomed Central}


CCA to chemotherapy and radiotherapy is a major problem [1]. The discovery and development of chemotherapeutics that are effective for the treatment and control of CCA is urgently needed.

Throughout history, natural products have afforded a rich repository of remedies with diverse chemical structures and bioactivities against several heath disorders including cancer. It is estimated that 122 drugs from 94 plant species have been discovered through ethnobotanical leads [2]. Additionally, the use of herbs as complementary and alternative medicine has increased dramatically in the last 20-25 years. According to the World Health Organization (WHO), traditional medicines are relied upon by $65-80 \%$ of the world's population for their primary health care needs [2]. In a previous study [3], we screened a total of 28 plants and 5 herbal formulations used in Thai traditional medicine for the treatment of various ailments for their cytotoxic activities against human CCA cell line CL-6. Ethanolic extracts of 5 plants (rhizomes of Zingiber officinale Roscoe and Atractylodes lancea thung. DC, fruits of Piper chaba Hunt., flowers of Mesua ferrea, and leaves of Kaemferia galangal) and 1 herbal formulation (Pra-SaPrao-Yhai) showed promising activities against CL-6 cell line with $\mathrm{IC}_{50}$ (concentration that inhibits cell growth by $50 \%)$ values of less than $50 \mu \mathrm{g} / \mathrm{ml}$.

In our effort to search for new herbal medicines with promising activity against CCA, we further investigated the in vivo anti-CCA, including the pharmacological activities (motor coordination, antihypertension, analgesia, anti-inflammation, anti-ulcer, and anti-pyrexia) of the ethanolic extracts of rhizomes of Zingiber officinal Roscoe (ZO), Atractylodes lancea thung. DC (AL), fruits of Piper chaba Hunt. (PC), and Pra-SaPrao-Yhai formulation (PPF) in CCA-xenograft nude mouse model. Due to the potential therapeutic interest for the treatment of cancer, the anti-CCA and pharmacological activities of curcumin (CUR), the phenolic compound isolated from rhizome of Curcuma longa Linn. was also investigated. ZO, commonly known as ginger, is a familiar condiment for various foods and beverages and is used in folk medicine in Asia and in tropical areas for various purposes such as relief for colds, fevers, and digestive problems and as treatment for nausea and vomiting as well as for arthritis. Some pungent constituents present in $\mathrm{ZO}$ possess potent antioxidant and anti-inflammatory activities and some of them exhibit cancer preventive activity in experimental carcinogenesis [4]. AL, the dried rhizome of $A$. lancea thung. DC called "Cang Zhu" in China or "Khod-Kha-Mao" in Thailand, has traditionally been used as a stomachic in China and Japan [5]. PC, the fruit of P. chaba Hunt. commonly called "Dee Plee", has been used in Thai medicine as an anti-flatulent, expectorant, carminative, antitussive, antifungal, uterus contracting agent, sedative-hypnotic, appetizer, counter-irritant, and is also useful in asthma, bronchitis, fever, and inflammation [6]. PPF is a Thai traditional medicine used for the treatment of fever in children [7]. This remedy consists of a mixture of various parts of 18 medicinal plants as described in Table 1.

\section{Results}

\section{Toxicity study}

For CUR, ZO, and AL, the maximum tolerated, including the medium and low dose levels that produced no significant sign of toxicity or death in the acute and sub-acute toxicity tests, were 5,000, 3,000, and 1,000 $\mathrm{mg} / \mathrm{kg}$ body weight, respectively. The maximum tolerated, medium and low dose levels of PPF, were 4,000, 2,000 , and $1,000 \mathrm{mg} / \mathrm{kg}$ body weight. The corresponding dose levels for PC were 1,000, 500, and $100 \mathrm{mg} / \mathrm{kg}$ body weight, respectively. In all these cases, no significant toxicity, except stomach irritation and general CNS depressant signs (reduced alertness and locomotion and diminished response to touch and balance) was observed. Stomach irritation was observed in all animals immediately after feeding them with the highest dose of test materials but the symptom subsided within 2 hours of administration.

\section{Anti-cholangiocarcinoma activity Tumor volume}

To assess the inhibitory activities of the test materials (CUR compound and plant extracts) on tumor growth, CL-6 cells were injected subcutaneously into the lower flanks of the CCA-xenografted nude mice. Tumor growth inhibition was most evident in the mice treated with AL at all dose levels, of which less than $10 \%$ of the tumor size of the control group was observed on day 40 (Figure 1). The highest dose level $(5,000 \mathrm{mg} / \mathrm{kg}$ body weight) of CUR, ZO, PC, and PPF exhibited low activities on day $48(40.5,35.8,16.1$, and $21.2 \%$ tumor volume of the control group, respectively). Mean ( \pm SEM) of tumor volumes for the control and the groups treated with 5-FU, CUR, ZO, AL, PC, and PPF were $20,661 \pm 126,15,789 \pm 101,12,290 \pm 144,13,270 \pm 130$, $550 \pm 13,17,347 \pm 116$, and $16,290 \pm 116 \mathrm{~mm}^{3}$, respectively. Representative tumors of CCA-xenografted mice following administration of test materials are shown in Figure 2.

\section{Survival time}

CCA-xenografted nude mice receiving AL at all dose levels had a significant $(p<0.001)$ prolongation of survival time (mean \pm SEM) over 80 days $(83.3 \pm 0.88$ days $)$ after tumor transplantation compared with the untreated group $(40.0 \pm 0.57$ days). The survival time of mice receiving 5 -FU, CUR, $\mathrm{ZO}, \mathrm{PC}$, and PPF were 55.0 
Table 1 Medicinal plants and herbal formulations under investigation

\begin{tabular}{|c|c|c|c|c|}
\hline Family & Plant & $\begin{array}{l}\text { Part } \\
\text { used }\end{array}$ & $\begin{array}{l}\text { Voucher } \\
\text { specimen }\end{array}$ & Thai traditional Use \\
\hline Zingiberaceae & Zingiber officinale Roscoe. & $\mathrm{Rh}$ & SKP 206261501 & $\begin{array}{l}\text { Treatment of hypercholesteremia and high level } \\
\text { triglyceride }\end{array}$ \\
\hline Compositae & Atractylodes lancea (Thung.) DC. & $\mathrm{Rh}$ & SKP 051011201 & Treatment of fever, colds, flu, sore throat \\
\hline Piperaceae & Piper chaba Hunt. & $\mathrm{Fr}$ & SKP 146160301 & Used as carminative, antidiarrheal \\
\hline \multicolumn{5}{|c|}{ Composition of Pra-Sa Prao-Yhai formulation: } \\
\hline Compositae & Artemisia annua Linn. & $\mathrm{Rh}$ & SKP 051010101 & Treatment of fever, hemorrhoids \\
\hline Compositae & Atractylodes lancea (Thung.) DC. & $\mathrm{Rh}$ & SKP 051011201 & Treatment of fever, colds, flu, sore throat \\
\hline Cruciferae & Asclepias curassavica Linn. & $\mathrm{Fl}$ & SKP 057121901 & Used as analgesic \\
\hline Dracaenaceae & Dracaena loureiri Gagnep. & $\mathrm{St}, \mathrm{Ba}$ & SKP 065041201 & Treatment of cough, fever, inflammation \\
\hline Guttiferae & Mammea siamensis Kosterm. & $\mathrm{Fl}$ & SKP 083131901 & Restorative \\
\hline Guttiferae & Mesua ferrea Linn. & $\mathrm{Fl}$ & SKP 083130601 & Treatment of dyspepsia \\
\hline Myristicaceae & Myristica fragrans Houtt. & Sd & SKP 121130601 & Treatment of uterus pain, diarrhea \\
\hline Myrtaceae & $\begin{array}{c}\text { Syzgium aromaticum (L.) Merr. \& L.M. } \\
\text { Perry }\end{array}$ & $\mathrm{FI}$ & SKP 123190101 & Treatment of toothache, bacterial infection \\
\hline Nelumbonaceae & Nigella sativa Linn. & $\mathrm{Sd}$ & SKP 160141901 & Treatment of jaundice \\
\hline Sapotadeae & Mimusops elengi Linn. & $\mathrm{FI}$ & SKP 171130501 & Used as cordial, tonic. Treatment of syncope \\
\hline Umbelliferae & Angelica dahurica Benth. & Rt & SKP 199010401 & Used as antipyretic, antiasthma, anticough \\
\hline Umbelliferae & Angelica sinensis (Oliv.) Diels & $\mathrm{Rh}$ & SKP 199010901 & Treatment of bronchitis pleurisy \\
\hline Umbelliferae & Anethum graveolens Linn. & $\mathrm{Rt}, \mathrm{Fr}$ & SKP 199010701 & Used as carminative. Treatment of eye pain \\
\hline Umbelliferae & Cuminum cyminum Linn. & $\mathrm{Sd}$ & SKP 199030301 & Treatment of dyspepsia, diarrhoea and jaundice \\
\hline Umbelliferae & Foeniculum vulgare Mill. var. dulce Alef. & $\mathrm{Sd}$ & SKP 199062201 & Used as analeptic \\
\hline Umbelliferae & $\begin{array}{l}\text { Ligusticum sinense Oliv. cv. } \\
\text { Chuanxiong }\end{array}$ & $\mathrm{Rh}$ & SKP 199121901 & $\begin{array}{c}\text { Treatment of urinary bladder channel, , headache, } \\
\text { neurodermatitis }\end{array}$ \\
\hline Zingiberaceae & Amomum testaceum Ridl. & $\mathrm{Sd}$ & SKP 206011101 & Used as carminative, antibacterial \\
\hline Zingiberaceae & Kaempferia galangal & Lf & SKP 206110701 & Antinociceptive, anti-inflammatory \\
\hline
\end{tabular}

$\pm 0.87,64.3 \pm 0.67,64.7 \pm 1.76,43.0 \pm 2.08$, and $69.7 \pm$ 0.88 days, respectively (Figure 3 ).

\section{Histopathology}

Histopathological findings revealed prominent inhibition of lung metastasis by AL at the highest dose of 5,000 $\mathrm{mg} / \mathrm{kg}$ body weight. Lung metastasis occurred in both the untreated and treated mice but the intensity of lung metastasis was significantly lower following a high dose $\mathrm{AL}$, with an average of less than $5 \%$ of the total lung mass. In contrast, the metastasis covered about $90 \%$ of the total lung mass of the untreated mice (Figure 4). Mice receiving 5-FU, CUR, PC, and PPF developed lung metastasis of $50,60,50,80$, and $40 \%$ of the total lung mass, respectively.

\section{Pharmacological activities Motor coordination activity}

Compared with the untreated group, a high dose level of CUR, ZO, AL, PC, and PPF produced a significant $(p<$ $0.001)$ interference with muscle relaxation similar to that produced by $4 \mathrm{mg} / \mathrm{kg}$ body weight diazepam (Figure $5)$. The mean $( \pm$ SEM) fall off time in the untreated and the groups treated with diazepam, high dose level of
CUR, ZO, AL, PC, and PPF were at $353.3 \pm 11.5,25.5 \pm$ $1.8,75.6 \pm 2.9,58.4 \pm 2.4,35.4 \pm 2.5,41.9 \pm 2.7$, and $37.8 \pm 2.6 \mathrm{sec}$, respectively.

\section{Antihypertensive activity}

High dose CUR, AL, PC, and the reference drug propanolol $(10 \mathrm{mg} / \mathrm{kg}$ body weight $)$ significantly $(p<0.001)$ decreased systolic (sBP) and diastolic (dBP) blood pressure of rats following treatment with adrenaline (Table 2). Propanolol (10 mg/kg body weight) and all doses of AL significantly $(p<0.001)$ reduced the heart rate of rats compared with the baseline. For $\mathrm{PC}$, only medium (500 mg/kg body weight) and high $(1,000 \mathrm{mg} / \mathrm{kg}$ body weight) dose levels significantly $(p<0.001)$ decreased heart rate. PPF and CUR had no effect on heart rate reduction (Table 3 ). The effect of all test materials on arterial blood pressure was similar to that observed with the heart rate (Table 4).

\section{Analgesic activity}

The central analgesic activities (hot plate test) of the test materials were supported by the results of the hot plate tests. Oral administration of a high dose level of PPF produced a significant $(p<0.001)$ prolongation of the latency time to the heat stimulus (with potency of 


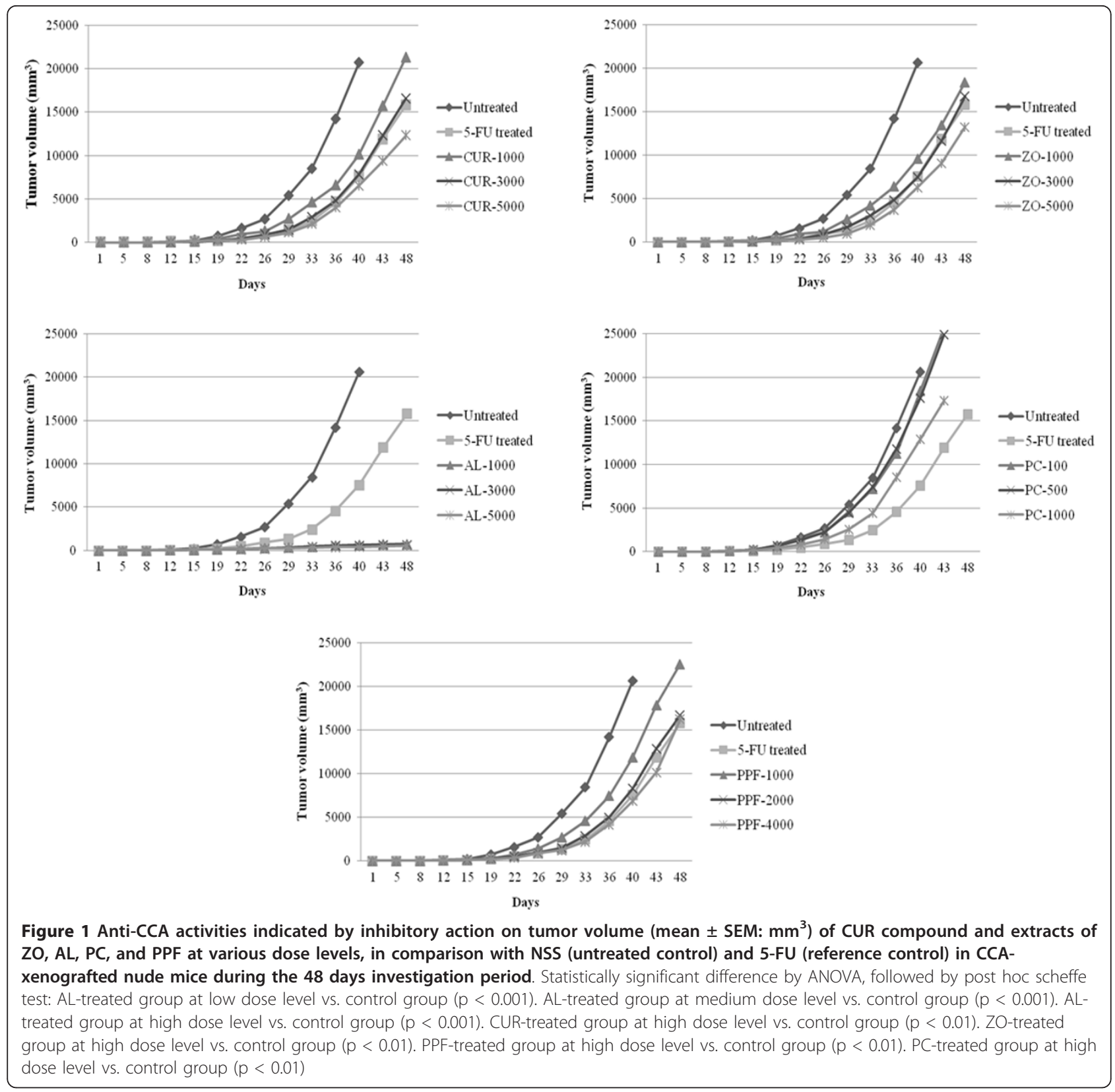

about $50 \%$ of $5 \mathrm{mg} / \mathrm{kg}$ body weight morphine) compared with the untreated control, starting $30 \mathrm{~min}$ until 60 min after administration. CUR, AL, and PC did not produce any significant central analgesic activities (Figure 6).

For peripheral analgesic activity (Writhing test), oral administration of CUR compound at all dose levels significantly $(p<0.01)$ inhibited the number of writhings and stretching induced by $0.6 \%$ acetic acid given by intraperitoneal injection with a potency of about $70-80 \%$ of aspirin $(200 \mathrm{mg} / \mathrm{kg}$ body weight). No significant peripheral analgesic activity was observed with AL, PC, and PPF (Figure 7).

\section{Anti-inflammatory activity}

Compared with the untreated control, indomethacin at a dose of $10 \mathrm{mg} / \mathrm{kg}$ body weight significantly $(p<0.001)$ reduced the paw edema volume induced by carrageenan, starting three hours after administration. Similarly, PPF at all dose levels also produced a significant $(p<0.01)$ antiinflammatory activity. AL exhibited significant $(p<0.01)$ activity only at a high dose level whereas CUR exhibited significant activity at medium and high dose levels (Figure 8). Anti-ulcer activity

The anti-ulcer activities of all test materials on ethanolinduced gastric lesion model are shown in Figure 9. Significant reduction (96.47-98.24\%) of ulcer size was 


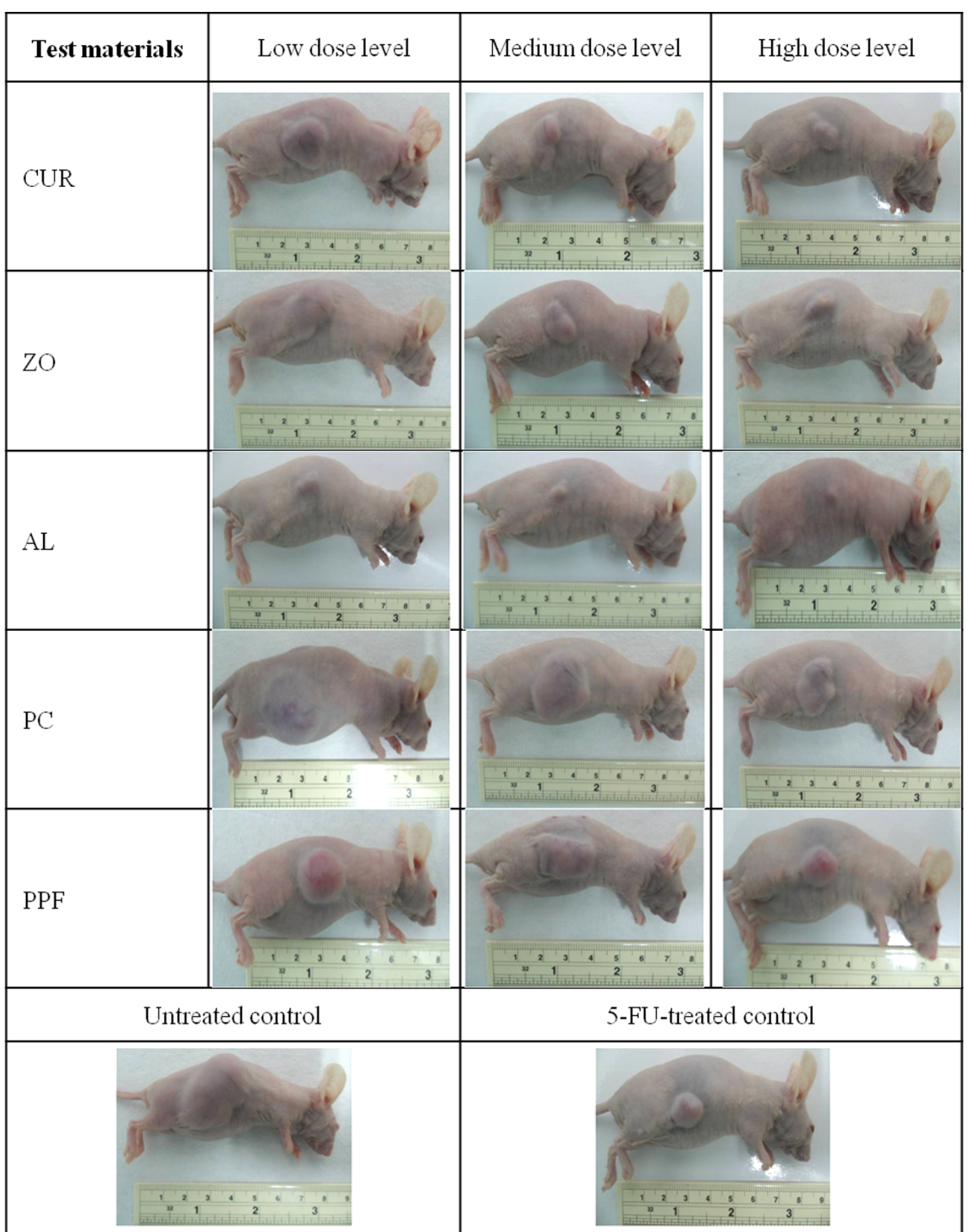

Figure 2 Representative tumors of CCA-xenografted nude mice following treatment with the test materials (CUR compound and extracts of ZO, AL, PC, and PPF at various dose levels) in comparison with untreated control and 5-FU (reference control).

observed in rats pre-treated with AL $(p<0.001)$ and CUR $(p<0.001)$ at all dose levels compared to the untreated control. Their potencies of activity were comparable to the reference drug omeprazole given at a dose of $20 \mathrm{mg} / \mathrm{kg}$ body weight (93.04\%) (Figure 10).

\section{Antipyretic activity}

The experimental rats showed a mean increase in about $1.4^{\circ} \mathrm{C}$ of rectal temperature, 17 hours after Brewer's yeast injection. PPF at $2,000 \mathrm{mg} / \mathrm{kg}$ body weight, and $\mathrm{ZO}$ and $\mathrm{AL}$ at $5,000 \mathrm{mg} / \mathrm{kg}$ body weight produced a 


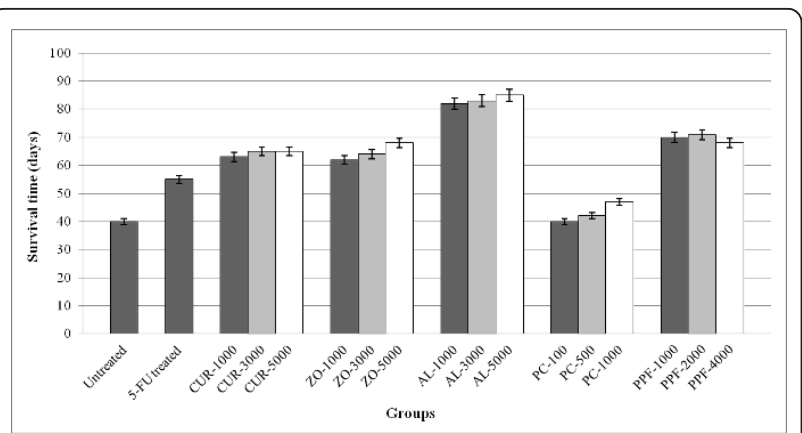

Figure 3 Anti-CCA activities indicated by prolongation of survival time (mean \pm SEM), of CUR compound and extracts of ZO, AL, PC, and PPF at various dose levels, in comparison with NSS (untreated control) and 5-FU (reference control) in CCAxenografted nude mice during the 85 days investigation period. Statistically significant difference by ANOVA, followed by post hoc scheffe test: AL-treated group at low dose level vs. control group $(p<0.001)$. AL-treated group at medium dose level vs. control group $(p<0.001)$. AL-treated group at high dose level vs. control group $(p<0.001)$.

significant $(p<0.01)$ antipyretic activity at 5 hours after administration, whereas PPF at 4,000 $\mathrm{mg} / \mathrm{kg}$ and aspirin at $200 \mathrm{mg} / \mathrm{kg}$ body weight showed significant antipyretic activity throughout the observation period starting from 3 up to 6 hours (Figure 11).

\section{Discussion}

The present study demonstrated promising anticancer activity against CCA in nude mouse xenograft model of the ethanolic extract of AL at all dose levels, as well as the extracts of $\mathrm{ZO}, \mathrm{PPF}$, and CUR compound at the highest dose level. PC produced no significant anti-CCA activity. Results from the acute and subacute toxicity tests both in mice and rats indicated safety profiles of all test materials in a broad range of dose levels. No significant toxicity, except stomach irritation and general CNS depressant signs (reduced alertness and locomotion, and diminished response to touch and balance), was observed. Stomach irritation occurred in all animals immediately after feeding them with a high dose of the test materials. Investigation of pharmacological activities of the test materials revealed promising anti-inflammatory (ZO, PPF, and AL), analgesic (CUR and PPF), antipyretic (CUR and $A L)$, antihypertensive ( $\mathrm{ZO}$ and $A L)$, and anti-ulcer (CUR, ZO, and AL) activities.

The ethanolic extract of AL was shown to possess the most potent anti-CCA activity similar to 5-FU with regards to the reduction of tumor mass, prolongation of survival time, and inhibition of lung metastasis. All dose levels significantly reduced tumor size (by 97.3\%), prolonged survival time (by 208.5\%), and inhibited lung metastasis (by $95 \%$ of total lung mass) compared with the untreated control. To the best of our knowledge, the present study is the first study that demonstrated the anticancer activity of AL. Interestingly, AL extract exhibited prominent inhibitory effect on lung metastasis. Metastasis is one of the major problems in the treatment of several cancer types. In severe stage CCA, metastatic tumors in the lungs are CCA cancers which developed in the lung tissues by spreading from the liver origin through the bloodstream or lymphatic system to the lungs. Histopathological examination at autopsy revealed lung metastasis in all mice following xenografting with CL-6. Significant reduction of lung metastasis to only $5 \%$ of the total lung mass was observed in the xenografted mice treated with AL (Figure 4) whereas metastasis of more than $90 \%$ of the total lung mass was found in the untreated mice. The antimetastatic action of AL corresponded well with its observed antihypertensive effects (reduction of systolic and diastolic blood pressure, heart rate, and mean arterial pressure). Furthermore, AL also exhibited anti-ulcer (all dose levels), anti-inflammatory (high dose), and antipyretic (high dose) activities. The observed significant anti-ulcer activity (96-98\%) of AL confirms its use to improve stomach damage partly through anti-ulcer effects [8]. This anti-ulcer activity was more potent than the reference drug omeprazole given at a dose of 20 $\mathrm{mg} / \mathrm{kg}$ body weight. The compound 2-[(2'E)-3',7'dimethyl-2',6'-octadienyl]-4-methoxy-6-methylphenol isolated from the rhizome of AL showed strong inhibitory effects on 5-lipoxygenase (5-LOX) and cyclooxygenase-1 (COX-1) [9], the two key enzymes responsible for the metabolism of arachidonic acid, either to prostaglandins and thromboxanes or to leukotrienes, which play a central role in the regulation of different physiological processes, but also cause pain, inflammation, and hypersensitivity.

Significant anti-CCA activity of rhizome extract of $\mathrm{ZO}$ was also observed in the xenograft mouse model. High dose ZO significantly reduced tumor volume (by $35.8 \%$ ), and all dose levels significantly prolonged survival time (by $161.5 \%$ ) compared with the control group. Inhibition of lung metastasis by about half was seen at high dose. Furthermore, the extract possessed anti-inflammatory at all dose levels. In our previous study, the anti-CCA activity of $\mathrm{ZO}$ was demonstrated in OV/dimethylnitrosamine induced-CCA hamster model [10]. The extract significantly prolonged survival time and survival rate of the cancerous animals. The anticancer properties of $\mathrm{ZO}$ have been attributed to the presence of certain pungent vallinoids, viz. [6]-gingerol and [6]-paradol, as well as some other constituents like shogaols and zingerone [11]. A number of mechanisms that may be involved in the chemopreventive activity of $\mathrm{ZO}$ and its components have been reported from the laboratory studies in various experimental models [11]. Various studies have 


\begin{tabular}{|c|c|c|}
\hline Test materials & $\begin{array}{c}\text { Histopathology of } \\
\text { lung metastasis } \\
\end{array}$ & $\begin{array}{l}\text { \% Metastasis } \\
\text { (of lung mass) }\end{array}$ \\
\hline CUR (High dose) & & $60 \%$ \\
\hline $\mathrm{ZO}$ (High dose) & & $50 \%$ \\
\hline AL (High dose) & & $\leq 5 \%$ \\
\hline PC (High dose) & & $80 \%$ \\
\hline PPF (High dose) & & $40 \%$ \\
\hline Untreated control & & $\geq 90 \%$ \\
\hline $\begin{array}{l}\text { Reference control } \\
(5-\mathrm{FU})\end{array}$ & & $50 \%$ \\
\hline
\end{tabular}

Figure 4 Representative histopathology of lung metastasis of CCA-xenografted nude mice following treatment with the test materials (CUR compound and extracts of ZO, AL, PC, and PPF at various dose levels) in comparison with untreated control and 5-FU (reference control). \% Metastasis of lung mass represents mean ( \pm SEM) from 6 mice for each group.

shown that a wide range of $\mathrm{ZO}$ constituents inhibit production of nitric oxide, inflammatory cytokines and enzymes prostaglandin synthase, and arachidonate-5-
LOX in a dose-dependent manner. The latter in turn, inhibits the synthesis of leukotrienes from both COX-1 and COX-2 and LOX, respectively [12]. ZO has also 


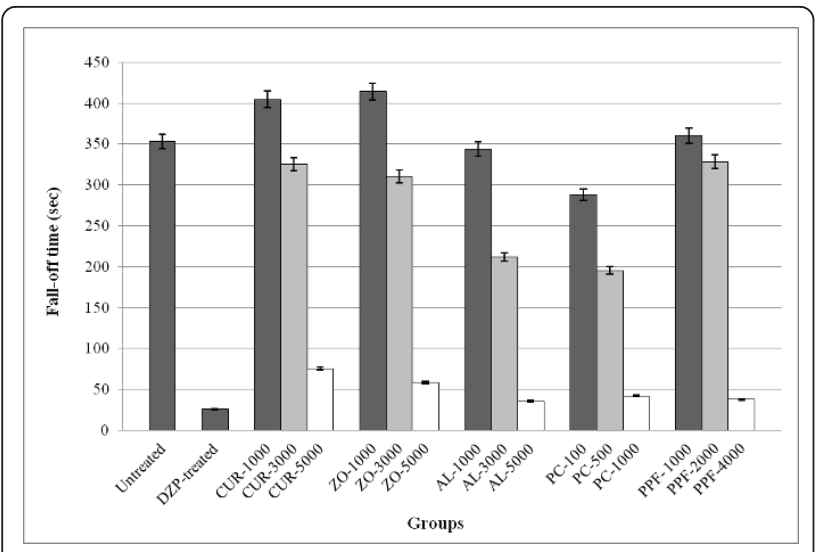

Figure 5 Effect of test materials on locomotive activity (represented by mean \pm SEM of fall-off time in seconds) in rats following treatment with the test materials (CUR compound and extracts of $\mathrm{ZO}, \mathrm{AL}, \mathrm{PC}$, and PPF at various dose levels) in comparison with untreated control and diazepam (reference control). Statistically significant difference by ANOVA, followed by post hoc scheffe test: CUR-treated group at high dose level vs. control group ( $p<0.001)$. ZO-treated group at high dose level vs. control group ( $p<0.001)$. AL-treated group at high dose level vs. control group $(p<0.001)$. PC-treated group at high dose vs. control group $(p<0.001)$ PPF-treated group at high dose vs. control group $(p<0.001)$. Diazepam-treated group vs. control group $(p<0.001)$. demonstrated a significant reduction of inflammation in animals compared with conventional drugs [12]. A significant anti-ulcer activity of the ethanolic extract of $\mathrm{ZO}$ was also observed. In a previous study [13], the gastroprotective effect of $50 \%$ ethanolic extract of $\mathrm{ZO}$ was assessed in rats in the ethanol and acetic acid-induced ulcer models at different doses $(500 \mathrm{mg} / \mathrm{kg}$ and $1.5-5 \mathrm{~g} /$ $\mathrm{kg}$ body weight, respectively). The extract showed a dose-dependent inhibition of the ulcer index in ethanol and acetic acid-induced ulcers. It prevented the oxidative damage of the gastric mucosa by blocking lipid peroxidation and by a significant decrease in superoxide dismutase and increase in catalase activity.

The anti-CCA activity of PPF extract was moderate; nevertheless, it exhibited diverse pharmacological activities. High dose PPF significantly reduced tumor volume and prolonged survival time compared with the untreated group. Inhibition of lung metastasis occurred on an average $60 \%$ of the lung mass. The anticancer activity of PPF is likely to be due to the activities of various components in the formulation. Recently, we demonstrated the cytotoxic activity against CL-6, a CCA cell line, of the two components of PPF: Mimusops elengi Linn. (flower) $\left(\mathrm{IC}_{50}=48.53\right.$ $\mu \mathrm{g} / \mathrm{ml}$ ) and Kaempferia galangal ("Proh-hom" in Thai;

Table 2 Effect of test materials and propanolol on systolic (sBP) and diastolic (dBP) blood pressure of rats

\begin{tabular}{|c|c|c|c|c|c|c|c|}
\hline \multirow[t]{3}{*}{ Group } & \multirow{3}{*}{$\begin{array}{c}\text { Dose } \\
\text { (mg/kg bw.) }\end{array}$} & \multicolumn{6}{|c|}{ Blood Pressure $(\mathrm{mmHg})$} \\
\hline & & \multicolumn{2}{|c|}{ Before induction of hypertension } & \multicolumn{2}{|c|}{ After induction of hypertension } & \multicolumn{2}{|c|}{ After treatment of hypertension } \\
\hline & & sBP & $\mathrm{dBP}$ & sBP & $\mathrm{dBP}$ & sBP & $\mathrm{dBP}$ \\
\hline Normal & - & $118 \pm 0.4$ & $81 \pm 0.3$ & $120 \pm 0.3$ & $82 \pm 0.4$ & $120 \pm 0.3^{*}$ & $81 \pm 0.4^{*}$ \\
\hline Untreated control & - & $119 \pm 0.5$ & $80 \pm 0.4$ & $178 \pm 0.4$ & $128 \pm 0.4$ & $181 \pm 0.6$ & $137^{*} \pm 0.4$ \\
\hline Propanolol-treated & 10 & $120 \pm 0.6$ & $81 \pm 0.3$ & $177 \pm 0.4$ & $131 \pm 0.5$ & $135 \pm 0.4^{*}$ & $95 \pm 0.4^{*}$ \\
\hline \multirow[t]{3}{*}{ CUR } & 1000 & $119 \pm 0.5$ & $82 \pm 0.3$ & $178 \pm 0.3$ & $130 \pm 0.4$ & $164 \pm 0.4$ & $126 \pm 0.3$ \\
\hline & 3000 & $119 \pm 0.4$ & $79 \pm 0.4$ & $180 \pm 0.4$ & $131 \pm 0.5$ & $152 \pm 0.3$ & $121 \pm 0.4$ \\
\hline & 5000 & $118 \pm 0.4$ & $78 \pm 0.3$ & $179 \pm 0.4$ & $130 \pm 0.4$ & $136 \pm 0.4^{*}$ & $101 \pm 0.4^{*}$ \\
\hline \multirow[t]{3}{*}{ Zo } & 1000 & $119 \pm 0.5$ & $81 \pm 0.3$ & $178 \pm 0.5$ & $130 \pm 0.5$ & $168 \pm 0.3$ & $119 \pm 0.3$ \\
\hline & 3000 & $120 \pm 0.5$ & $80 \pm 0.3$ & $180 \pm 0.4$ & $129 \pm 0.5$ & $163 \pm 0.5$ & $120 \pm 0.5$ \\
\hline & 5000 & $120 \pm 0.4$ & $81 \pm 0.4$ & $181 \pm 0.5$ & $128 \pm 0.4$ & $162 \pm 0.4$ & $119 \pm 0.4$ \\
\hline \multirow[t]{3}{*}{$A L$} & 1000 & $121 \pm 0.5$ & $79 \pm 0.4$ & $180 \pm 0.4$ & $131 \pm 0.5$ & $155 \pm 0.3$ & $109 \pm 0.4$ \\
\hline & 3000 & $118 \pm 0.4$ & $82 \pm 0.4$ & $179 \pm 0.5$ & $126 \pm 0.5$ & $156 \pm 0.4$ & $105 \pm 0.5$ \\
\hline & 5000 & $119 \pm 0.3$ & $81 \pm 0.3$ & $177 \pm 0.4$ & $169 \pm 0.4$ & $134 \pm 0.4^{*}$ & $98 \pm 0.3^{*}$ \\
\hline \multirow[t]{3}{*}{ PC } & 100 & $117 \pm 0.3$ & $79 \pm 0.4$ & $180 \pm 0.4$ & $127 \pm 0.5$ & $180 \pm 0.5$ & $126 \pm 0.4$ \\
\hline & 500 & $118 \pm 0.4$ & $81 \pm 0.3$ & $177 \pm 0.3$ & $129 \pm 0.4$ & $170 \pm 0.4$ & $122 \pm 0.4$ \\
\hline & 1000 & $120 \pm 0.5$ & $80 \pm 0.4$ & $179 \pm 0.4$ & $128 \pm 0.4$ & $139 \pm 0.3^{*}$ & $113 \pm 0.4^{*}$ \\
\hline \multirow[t]{3}{*}{ PPF } & 1000 & $119 \pm 0.4$ & $82 \pm 0.4$ & $179 \pm 0.4$ & $131 \pm 0.4$ & $169 \pm 0.5$ & $117 \pm 0.3$ \\
\hline & 3000 & $120 \pm 0.5$ & $79 \pm 0.4$ & $180 \pm 0.5$ & $130 \pm 3.3$ & $162 \pm 0.4$ & $121 \pm 0.4$ \\
\hline & 4000 & $119 \pm 0.4$ & $80 \pm 0.3$ & $181 \pm 0.5$ & $128 \pm 0.5$ & $162 \pm 0.4$ & $120 \pm 0.5$ \\
\hline
\end{tabular}

Data are presented as mean \pm SEM values

*Statistically significant difference with baseline by paired t-test:

$S B P$ and $A B P$ of CUR-treated group at high dose level $(p<0.001)$

$S B P$ and $A B P$ of AL-treated group at high dose level $(p<0.001)$

$S B P$ and $A B P$ of $P C$-treated group at high dose level $(p<0.001)$

$S B P$ and $d B P$ of propanolol-treated group at high dose level $(p<0.001)$ 
Table 3 Effect of test materials and propanolol (reference control) on heart rate of rats

\begin{tabular}{|c|c|c|c|c|}
\hline \multirow[t]{2}{*}{ Group } & \multirow{2}{*}{$\begin{array}{c}\text { Dose } \\
\text { (mg/kg bw.) }\end{array}$} & \multicolumn{3}{|c|}{ Heart rate (beat $/ \mathrm{min})$} \\
\hline & & Before induction of hypertension & After induction of hypertension & After treatment of hypertension \\
\hline Normal & - & $412 \pm 4.3$ & $415 \pm 4.1$ & $409 \pm 4.5$ \\
\hline Untreated control & - & $399 \pm 4.1$ & $535 \pm 5.4$ & $570 \pm 5.8$ \\
\hline Propanolol-treated & 10 & $410 \pm 4.4$ & $520 \pm 5.5$ & $405 \pm 4.4$ \\
\hline \multirow[t]{3}{*}{ CUR } & 1000 & $411 \pm 4.5$ & $530 \pm 5.5$ & $530 \pm 5.5$ \\
\hline & 3000 & $401 \pm 4.2$ & $528 \pm 5.3$ & $518 \pm 5.6$ \\
\hline & 5000 & $390 \pm 3.9$ & $523 \pm 5.4$ & $471 \pm 4.3$ \\
\hline \multirow[t]{3}{*}{ ZO } & 1000 & $420 \pm 4.2$ & $526 \pm 4.9$ & $499 \pm 5.1$ \\
\hline & 3000 & $418 \pm 4.9$ & $531 \pm 5.7$ & $474 \pm 5.2$ \\
\hline & 5000 & $415 \pm 4.6$ & $530 \pm 5.5$ & $416 \pm 4.1^{*}$ \\
\hline \multirow[t]{3}{*}{ AL } & 1000 & $403 \pm 4.1$ & $544 \pm 5.4$ & $431 \pm 4.4^{*}$ \\
\hline & 3000 & $407 \pm 4.3$ & $540 \pm 5.6$ & $416 \pm 4.3^{*}$ \\
\hline & 5000 & $398 \pm 3.6$ & $528 \pm 5.3$ & $410 \pm 4.5^{*}$ \\
\hline \multirow[t]{3}{*}{ PC } & 100 & $409 \pm 4.0$ & $537 \pm 5.2$ & $540 \pm 5.6$ \\
\hline & 500 & $410 \pm 4.2$ & $519 \pm 5.3$ & $427 \pm 4.1^{*}$ \\
\hline & 1000 & $420 \pm 4.5$ & $509 \pm 5.3$ & $419 \pm 4.6^{*}$ \\
\hline \multirow[t]{3}{*}{ PPF } & 1000 & $412 \pm 4.5$ & $519 \pm 5.2$ & $559 \pm 5.8$ \\
\hline & 2000 & $398 \pm 4.7$ & $534 \pm 5.6$ & $544 \pm 5.7$ \\
\hline & 4000 & $405 \pm 4.4$ & $526 \pm 5.5$ & $536 \pm 5.4$ \\
\hline
\end{tabular}

Data are presented as mean \pm SEM values

*Statistically significant difference with baseline by paired t-test:

$S B P$ and $A B P$ of ZO-treated group at high dose level $(p<0.001)$

$S B P$ and $A B P$ of $A L$-treated group at all dose levels $(p<0.001)$

$s B P$ and $d B P$ of $P C$-treated group at medium and high dose levels $(p<0.001)$

leaf) $\left(\mathrm{IC}_{50}=37.36 \mu \mathrm{g} / \mathrm{ml}\right)$ [3]. In addition, previous in vitro and in vivo studies reported the anticancer potential of Nigella saliva (commonly known as black seed or black cumin) [14], Angelica sinensis (Oliv.) Diels [15], Anethum graveolens Linn. [16], Foeniculum vulgare Mill. [17], Angelica dahurica Benth. [18], Mammea siamensis Kosterm. [19], Myristica fragrans Houtt. [20], and Syzygium aromaticum Linn. (cloves) [21]. The bioactive compound derived from $N$. sativa oil is thymoquinone, which was shown to exhibit anti-tumor activities, including anti-proliferative and pro-apoptotic effects on cell lines derived from breast, colon, ovary, larynx, lung, myeloblastic leukemia, and osteosarcoma [22-26]. Mechanistically, thymoquinone reportedly induced apoptosis in tumor cells by suppressing $\mathrm{NF}-\kappa \mathrm{B}$, Akt activation and extracellular signal-regulated kinase signaling pathways, and also inhibits tumor angiogenesis [27]. Recently, the serine/threonine Polo-like kinases (Plk) which are over-expressed in many types of human cancers have been identified as targets for thymoquinone. Cytotoxic activity towards several cell lines in vitro including apoptotic activity was also shown with a novel polysaccharide isolated from a rhizome of $A$. sinensis (Oliv.) Diels named APS-1 d [15]. Among the coumarins isolated from the bark of M. siamensis Kosterm, theraphin
C showed the strongest inhibitory activity on cell proliferation in DLD-1 (colon cancer), MCF-7 (breast adenocarcinoma), HeLa (human cervical cancer), and NCI-H460 (human lung cancer) cell lines [19].

With regards to the pharmacological activities of PPF, anti-inflammatory and CNS suppression effects were observed at all doses, whereas reduction of blood pressure and analgesic effects were shown at high dose and antipyretic effect was shown at the medium dose level of $2,000 \mathrm{mg} / \mathrm{kg}$ body weight. Promising antipyretic, antihypertensive, anti-inflammatory, and analgesic activities of various components of PPF have previously been shown. For example, the seed of $N$. sativa was shown to exhibit antihypertensive property [14]. The anti-inflammatory action of nutmeg has been shown to be due to the myristicin that it contains [28]. Anti-inflammatory effect of thymoquinone from the seed of $N$. sativa was shown to be due to the inhibitory effect on eicosanoid generation, namely thromboxane B2 and leukotrienes B4, by inhibiting both COX and LOX enzymes, respectively [29]. The ethanol fractions of $A$. sinensis (Oliv.) Diels and $A$. dahurica were shown to exert an antiinflammatory effect through the suppression of NF- $\kappa \mathrm{B}$ dependent activity [30]. Flavonoids and stilbenoids 
Table 4 Effect of test materials and propanolol (reference control) on mean arterial blood pressure of rats

\begin{tabular}{|c|c|c|c|c|}
\hline \multirow[t]{2}{*}{ Group } & \multirow{2}{*}{$\begin{array}{c}\text { Dose } \\
\text { (mg/kg bw.) }\end{array}$} & \multicolumn{3}{|c|}{ Mean arterial pressure $(\mathrm{mmHg})$} \\
\hline & & Before induction of hypertension & After induction of hypertension & After treatment of hypertension \\
\hline Normal & - & $107 \pm 3.1$ & $110 \pm 3.4$ & $109 \pm 2.7$ \\
\hline Untreated control & - & $108 \pm 3.4$ & $143 \pm 2.7$ & $151 \pm 3.0$ \\
\hline Propanolol-treated & 10 & $110 \pm 3.2$ & $145 \pm 3.1$ & $116 \pm 2.5^{*}$ \\
\hline \multirow[t]{3}{*}{ CUR } & 1000 & $106 \pm 0.4$ & $145 \pm 0.3$ & $138 \pm 0.5$ \\
\hline & 3000 & $104 \pm 0.3$ & $146 \pm 0.4$ & $137 \pm 0.4$ \\
\hline & 5000 & $107 \pm 0.3$ & $148 \pm 0.3$ & $135 \pm 0.4$ \\
\hline \multirow[t]{3}{*}{ ZO } & 1000 & $105 \pm 0.3$ & $144 \pm 0.4$ & $135 \pm 0.5$ \\
\hline & 3000 & $107 \pm 0.4$ & $147 \pm 0.5$ & $137 \pm 0.3$ \\
\hline & 5000 & $106 \pm 0.3$ & $148 \pm 0.4$ & $119 \pm 0.3^{*}$ \\
\hline \multirow[t]{3}{*}{ AL } & 1000 & $105 \pm 0.3$ & $148 \pm 0.5$ & $118 \pm 0.4^{*}$ \\
\hline & 3000 & $107 \pm 0.4$ & $144 \pm 0.4$ & $120 \pm 0.4^{*}$ \\
\hline & 5000 & $106 \pm 0.3$ & $148 \pm 0.4$ & $122 \pm 0.3^{*}$ \\
\hline \multirow[t]{3}{*}{ PC } & 100 & $103 \pm 0.3$ & $147 \pm 0.3$ & $134 \pm 0.5$ \\
\hline & 500 & $105 \pm 0.4$ & $149 \pm 0.4$ & $124 \pm 0.4^{*}$ \\
\hline & 1000 & $105 \pm 0.4$ & $147 \pm 0.4$ & $125 \pm 0.4^{*}$ \\
\hline \multirow[t]{3}{*}{ PPF } & 1000 & $104 \pm 0.3$ & $145 \pm 0.4$ & $134 \pm 0.3$ \\
\hline & 2000 & $108 \pm 0.4$ & $146 \pm 0.5$ & $134 \pm 0.4$ \\
\hline & 4000 & $104 \pm 0.4$ & $143 \pm 0.5$ & $134 \pm 0.5$ \\
\hline
\end{tabular}

Data are presented as mean \pm SEM values

*Statistically significant difference with baseline by paired t-test:

$S B P$ and $A B P$ of ZO-treated group at high dose level $(p<0.001)$

$S B P$ and $d B P$ of $A L$-treated group at all dose levels $(p<0.001)$

$S B P$ and $A B P$ of $P C$-treated group at medium and high dose levels $(p<0.001)$

$S B P$ and $A B P$ of propanolol-treated group $(p<0.001)$

isolated from the stem wood of D. loureiri were shown to exhibit COX-1 and COX-2 inhibitory activity [31]. The anti-inflammatory mechanisms of byakangelicin, the active component of $A$. dahurica Benth, involve the inhibition of tumour necrosis factor- $\alpha$, histamine release, and of PGE2 through decreased COX-2, besides its potent antioxidant effects [32]. The analgesic activity of PPF observed in the present study was found to be centrally acting. The antinociceptive effects of $N$. sativa oil and the active compound thymoquinone were shown to be through indirect activation of the superspinal $\mathrm{mu}_{1}$ and kappa opioid receptors [33].

Recent studies have substantiated and provided scientific evidence regarding the prophylactic and therapeutic potential of CUR as anticancer in several types of cancer including colon, lung, breast, liver, and prostate. Interestingly, the anticancer activity of CUR against CCA in the hamster model was reported recently [34]. The compound exhibited an anticarcinogenic potential via increasing the survival of hamsters, suppression of the various events involved in multiple steps of carcinogenesis such as transcription factor, NF- $\kappa \mathrm{B}, \mathrm{AP}-1$, and STAT-3, and ability to suppress pro-inflammatory pathways on COX-2 and iNOS. In the present study, the CUR compound was shown to possess moderate anti-CCA activity. High dose significantly reduced tumor volume (by $40.5 \%$ ) and inhibited lung metastasis (by 60\%). All doses significantly prolonged survival time (by 160.8\%) compared with the control group. Undisputed scientific evidence suggests that CUR suppresses all three stages of carcinogenesis: initiation, promotion, and progression [34]. Due to a vast number of biological targets with virtually no side effects, CUR has achieved the potential therapeutic interest to cure immune related, metabolic diseases, and cancer. The intricate mechanism of action of CUR involves various biological targets $v i z$ transcription factors: NF-AT, AP-1, signal transducers and activator of transcription (STAT), p53 and kinases: mitogen-activated protein kinases, cytokines release, and the receptors found on different immune cell type. These actions of CUR greatly affect the innate and adaptive arms of immunity especially in the pathological conditions [34]. The peripheral analgesic and anti-ulcer effects were shown in this study following all dose levels of CUR. Surprisingly, no significant anti-inflammatory activity was observed. The analgesic activity of CUR is consistent with the previous findings of suppression of nociception in 

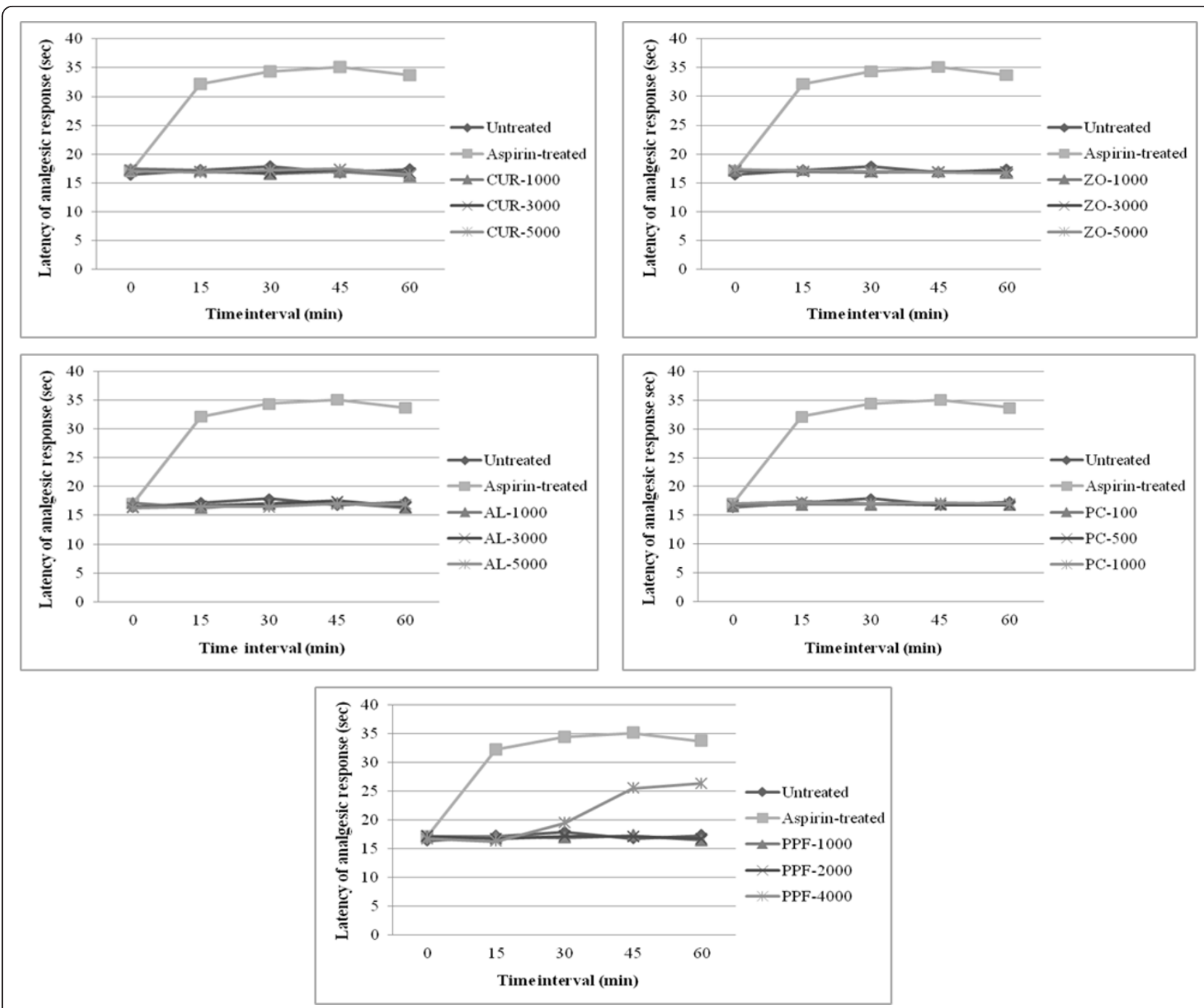

Figure 6 Central analgesic activity (represented by mean \pm SEM of analgesic response in hot plate test) of CUR compound and extracts of ZO, AL, PC, and PPF at various dose levels, in comparison with untreated control and aspirin (reference control). Statistically significant difference by ANOVA, followed by post hoc scheffe test: PPF-treated group at high dose level vs. control group $(p<0.01)$. Aspirintreated group vs. control group $(p<0.001)$.

both tail flick and acetic acid-induced writhing tests following intraperitoneal injection of CUR extract [35]. Tuorkey and Karolin (2009) [36] demonstrated the anti-ulcer activity of curcumin that was displayed by attenuating the different ulcerative effectors including gastric acid hypersecretion, total peroxides, myeloperoxidase (MPO) activity, IL-6, and apoptotic incidence.

\section{Conclusion}

The results suggest that plants used in Thai traditional medicine for the treatment of various ailments may provide reservoirs of promising candidate chemotherapeutics for the treatment of CCA. In addition, results from pharmacological activity tests rationalize the ethnomedical use of this plant in a number of ailments.
These plants have multiple pharmacological actions on various human physiological systems that would support the treatment of chronic disease like cancer. Moreover, the use of herbal medicines is safe compared with synthetic drugs. Further studies are required to determine the molecular mechanisms and active ingredients of all test materials particularly AL, which are responsible for their anti-CCA activities.

\section{Methods}

\section{Chemicals and reagents}

Commercial grade ethanol and acetic acid were purchased from RCI Labscan Co. Ltd. (Pathumwan, BKK, THA). The cell culture medium RPMI, fetal bovine serum (FBS), dimethylsulfoxide (DMSO), and the 


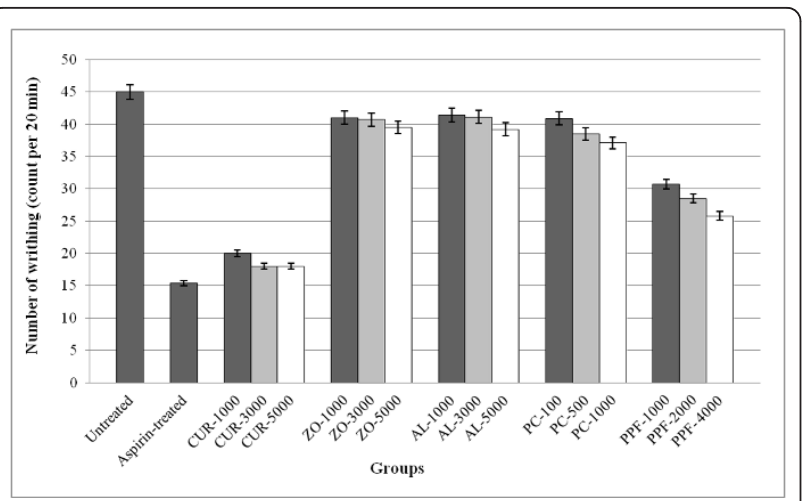

Figure 7 Peripheral analgesic activity (represented by mean \pm SEM) number of writhing and stretching in writhing test) of CUR compound and extracts of ZO, AL, PC, and PPF at various dose levels, in comparison with untreated control and aspirin (reference control). Statistically significant difference by ANOVA, followed by post hoc scheffe test: CUR-treated group at low dose level vs. control group $(p<0.01)$. CUR-treated group at medium dose level vs. control group $(p<0.001)$. CUR-treated group at high dose level vs. control group $(p<0.001)$. Aspirin-treated group vs. control group $(p<0.001)$.

antibiotics-antimycotics were purchased from Gibco BRL Life Technologies (Grand Island, NY, USA). Curcumin (CUR) compound, 5-fluorouracil (5-FU), propanolol, aspirin, indomethacin, omeprazole, paracetamol, brewer's yeast, $\lambda$-carrageenan, and Tween- 80 were purchased from Sigma-Aldrich Inc. (St. Louis, MO, USA). Adrenaline injection was purchased from the Government Pharmaceutical Organization of Thailand (GPO).

\section{Preparation of plant extracts}

Plant materials were collected from various parts of Thailand and some were purchased from city markets. Authentication of plant materials were carried out at the herbarium of the Department of Forestry, Bangkok, Thailand, where the herbarium vouchers have been kept. A duplicate set was also deposited in the herbarium of Southern Center of Thai Medicinal Plants at the Faculty of Pharmaceutical Sciences, Prince of Songkhla University, Songkhla, Thailand. Preparation of the ethanolic extracts of all plant materials were performed according to the previously described method [3]. All extracts were standardized using high performance liquid chromatography to examine the amounts of active ingredients. The ethanolic extract yields of ZO, AL, PC, and PPF were 4.3, 16.89, 10.89, and $18.66 \%$. Quantitative analysis of marker compounds of the ethanolic extracts of $\mathrm{ZO}$ (6-gingerol), AL ( $\beta$-eudesmol), PC (piperine), and PPF (acetoxychavicol acetate) revealed $6.18,6.64,7.0$, and $10.45 \%$ of the total crude extract, respectively.

\section{Cell line and culture}

The CCA cell line CL-6 used for in vivo tumor xenograft was cultured in RPMI medium supplemented with $10 \%$ heated fetal bovine serum and $100 \mathrm{IU} / \mathrm{ml}$ of antianti and were maintained at $37^{\circ} \mathrm{C}$ in a $5 \% \mathrm{CO}_{2}$ atmosphere with 95\% humidity.

\section{Animals}

Male and female ICR and BALB/c-nude mice (6 weeks of age, weighting 20-25 g) and Wistar albino rats (6 weeks of age, weighting 120-130 g) were purchased from The National Laboratory Animal Centre of Thailand. They were housed under standard conditions and fed with a stock diet and water ad libitum. Approval of the study protocol was obtained from the Ethics Committee for Research in Animals, Thammasat University, Thailand.

\section{Evaluation of acute and subacute toxicity}

Acute and subacute toxicity tests were performed in mice and rats according to the OECD guideline for chemicals with modification in order to obtain the three dose levels (maximum tolerated dose, medium dose, and low dose) of each test material which did not cause any sign of serious toxicity or death [37]. These three tolerated dose levels were further used for assessment of the anti-CCA and pharmacological activities of each test material. ICR mice and Wistar albino rats (5 males and 5 females for each group) were fed (via gastric gavage) with three dose levels (low, medium, and high) of the test materials (resuspended in a mixture of distilled water and Tween-80, 4:1, v:v). The maximum dose started from $5,000 \mathrm{mg} / \mathrm{kg}$ body weight. The control animals were fed with a mixture of distilled water and Tween-80. Animals were closely observed for signs of toxicity during the first 30 minutes, periodically during the first 24 hours and then daily for 14 days (acute toxicity) or 30 days (subacute toxicity). At the end of the observational period, all animals were sacrificed under ether anesthesia and vital organs (brain, heart, kidneys, liver, spleen, stomach, large and small intestine, and lungs) were removed from all animals for gross and histopathological examination.

\section{Assessment of anti-CCA activity in nude mouse xenograft model}

The CCA cell line CL- $6\left(1 \times 10^{6}\right.$ cells $)$ was used for xenografting all nude mice. Cells were removed from culture flask by trypsinization, collected in a $50 \mathrm{ml}$ conical tube and centrifuged at $100 \times \mathrm{g}$ for $10 \mathrm{~min}$. Supernatant was removed and cells were resuspended in $5 \mathrm{ml}$ of complete media and cell number was counted using hemocytochamber. Cells for injection were prepared by diluting cell suspension to obtain $1 \times 10^{6}$ cells $/ 200 \mu \mathrm{l}$ 


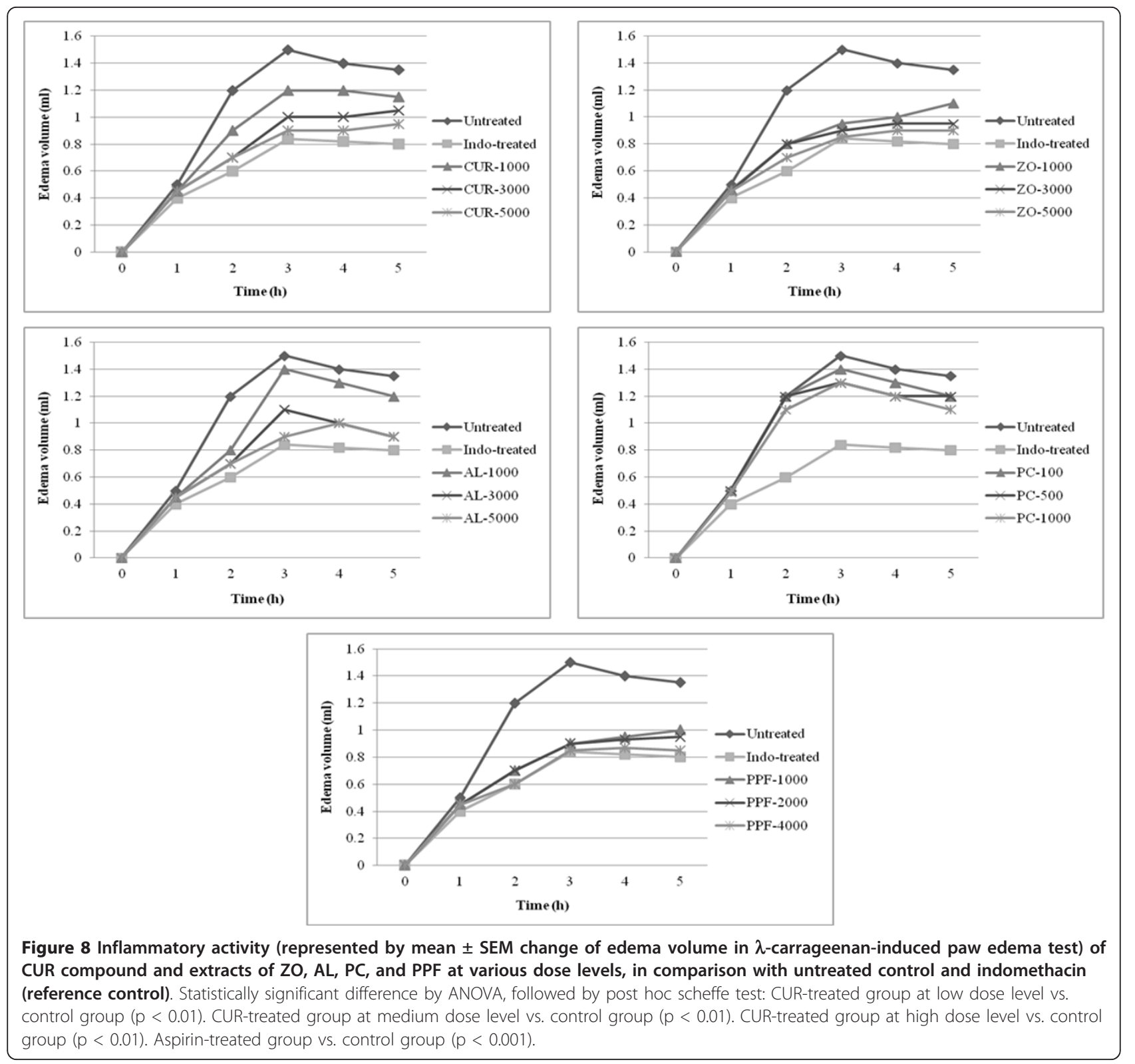

normal saline $(0.85 \% \mathrm{NaCl})$ and injected subcutaneously into the flanks of the nude mice $\left(1 \times 10^{6}\right.$ cells in 200 $\mu \mathrm{l})$. Tumors were allowed to develop for 14 days until they reached approximately $50 \mathrm{~mm}^{3}$ tumor volume. Tumor volume was measured using a caliper and body weight was recorded once every three days (Figure 12).

To evaluate the anti-CCA activity of CUR compound and each plant extract, CCA-xenografted nude mice were divided into groups of 6 males for each dose level, matched-pair according to tumor size and body weight after tumor nodules reached the volume of approximately to $50 \mathrm{~mm}^{3}$. All the test materials were given at the three dose levels (low, medium, and high) based on the maximum tolerated dose observed in the toxicity test. $\mathrm{AL}, \mathrm{ZO}$, and $\mathrm{CUR}$ were given at the doses of 1,000 (low), 3,000 (medium), and 5,000 (high) mg/ $\mathrm{kg}$ body weight. PC was given at the doses of 100 (low), 500 (medium), and 1,000 (high) $\mathrm{mg} / \mathrm{kg}$ body weight. PPF was given at the doses of 1,000 (low), 2,000 (medium), and 4,000 (high) $\mathrm{mg} / \mathrm{kg}$ body weight. Each test material was fed to animals by intragastric tube $(0.3 \mathrm{ml})$ daily for 30 days. The untreated and 5FU treated control groups were given an equal volume of normal saline daily for 30 doses and 5-FU $(40 \mu \mathrm{g} /$ $\mathrm{ml}$ ) for 14 doses, respectively. On day 0 (the day of first dose), 2, 5, 8, 11, 14, 18, 21, 24, and 28 animals were weighed on a triple-beam balance and tumor size was measured in two linear dimensions (maximum 


\begin{tabular}{|c|c|c|}
\hline Test materials & $\begin{array}{c}\text { Gross appearance of the } \\
\text { gastric mucosa }\end{array}$ & $\%$ Inhibition \\
\hline $\begin{array}{l}\text { CUR } \\
\text { (High dose) }\end{array}$ & & $98.24 \%$ \\
\hline $\begin{array}{l}\mathrm{ZO} \\
\text { (High dose) }\end{array}$ & & $86.16 \%$ \\
\hline $\begin{array}{l}\mathrm{AL} \\
\text { (High dose) }\end{array}$ & & $98.55 \%$ \\
\hline $\begin{array}{l}\mathrm{PC} \\
\text { (High dose) }\end{array}$ & & $51.61 \%$ \\
\hline $\begin{array}{l}\text { PPF } \\
\text { (High dose) }\end{array}$ & & $89.59 \%$ \\
\hline Untreated control & & $0 \%$ \\
\hline $\begin{array}{l}\text { Omeprazole-treated } \\
\text { control }\end{array}$ & & $93.04 \%$ \\
\hline
\end{tabular}

Figure 9 Observed ulcer area in gross appearance and inhibition percentage in rats.

longitudinal and transverse diameters) using calipers with accuracy of $0.1 \mathrm{~mm}$. The tumor volume was calculated from the formula: tumor volume $=$ (length) $(\text { width })^{2} / 2$.
Autopsy and histopathological examination

For both toxicity and anticancer activity evaluation, all internal organs were removed from the animals at autopsy and observed macroscopically. Samples were 

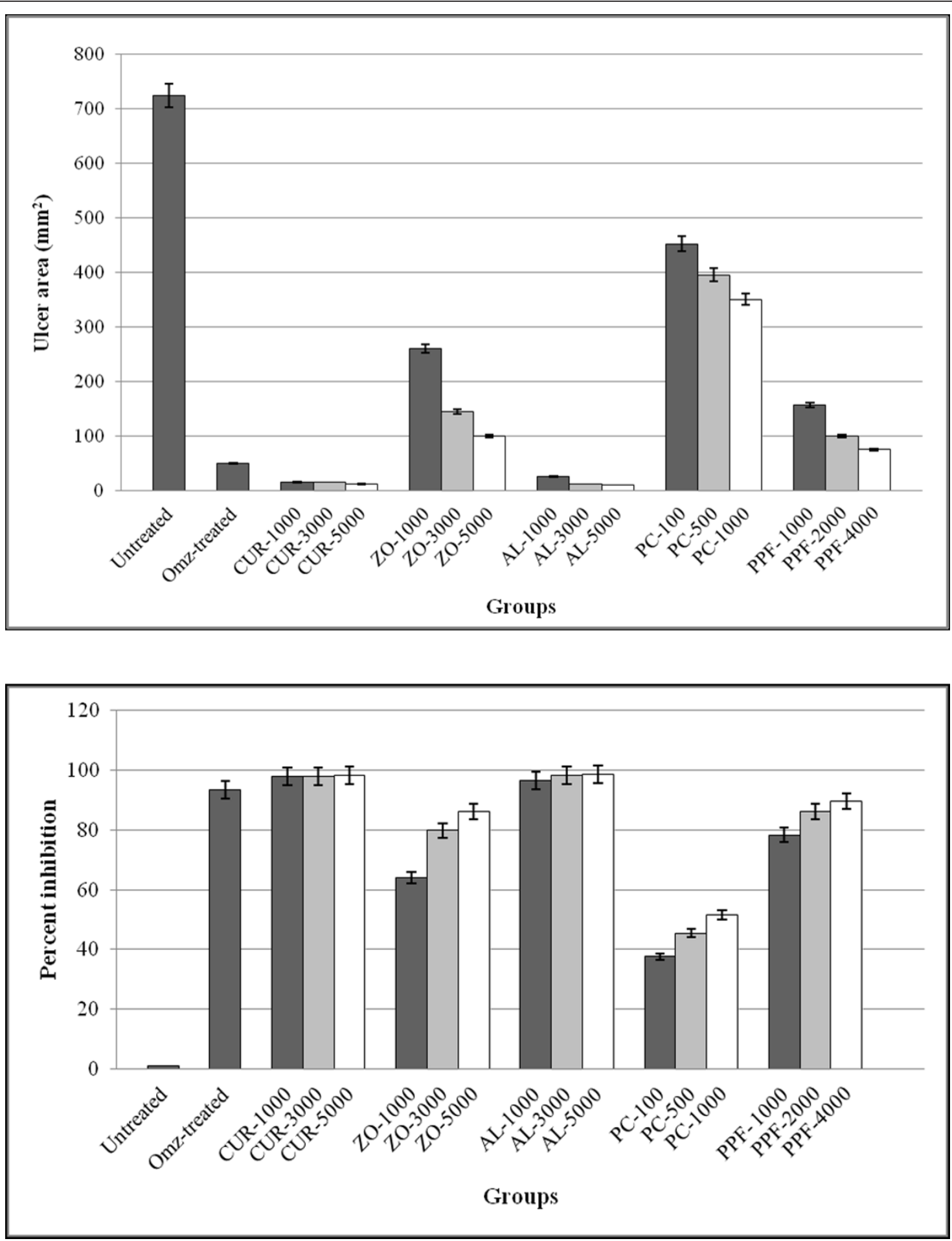

Figure 10 Anti-ulcer activity (represented by mean \pm SEM of ulcer area and \% inhibition of ulcer area in ethanol-induced gastric ulcer test) of CUR compound and extracts of ZO, AL, PC, and PPF at various dose levels, in comparison with untreated control and

omeprazole (reference control). Statistically significant difference by ANOVA, followed by post hoc scheffe test: CUR-treated group at low dose level vs. control group $(p<0.001)$. ZO-treated group at medium dose level vs. control group $(p<0.001)$. AL-treated group at high dose level vs. control group ( $p<0.001$ ). PPF-treated group at high dose level vs. control group $(p<0.001)$. Omeprazole-treated group vs. control group ( $p<$ $0.001)$. 


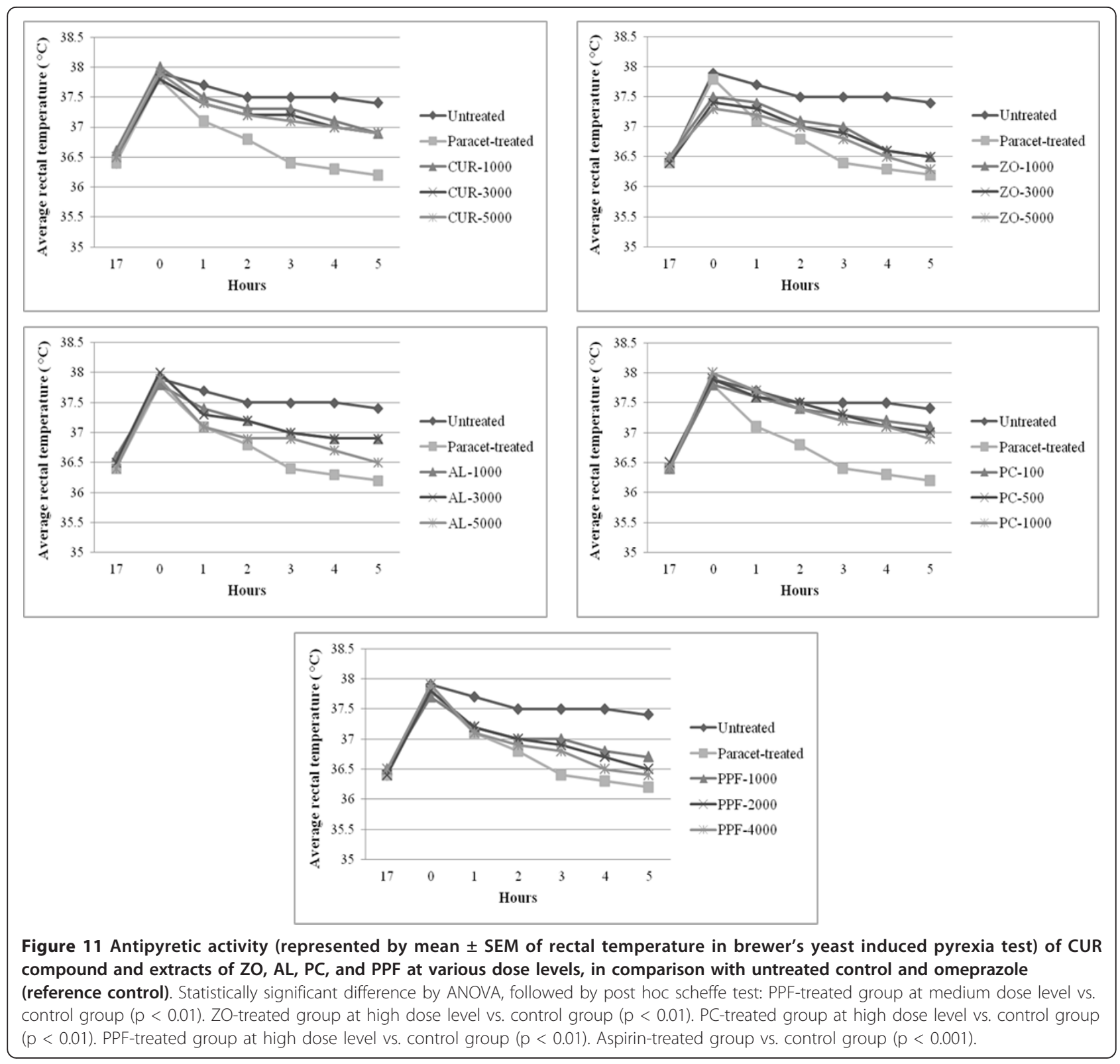

fixed with $10 \%$ formalin solution. Specimens were washed in phosphate buffer three times, then dehydrated in an ascending series of ethanol for 15 min each and embedded in paraffin, followed by sectioning and staining with hematoxylin and eosin [38].

\section{Assessment of pharmacological activities}

Each test material was administered orally to all animals (ICR mice or rats) in the form of suspension of water and $1 \%$ sodium carboxy methyl cellulose (SCMC). Animals were divided into groups of six males each. Each test material was given at the three dose levels (low, medium, and high) as described previously for the assessment of anti-CCA activities. The untreated control group received $10 \mathrm{ml} / \mathrm{kg}$ body weight of $1 \%$ SCMC while the positive control group received the reference drug for each test at an appropriate dose.

\section{Locomotive activity}

Rota-rod test was applied to assess the effect of CUR compound and plant extracts on motor coordination [39]. Mice were trained to remain for $3 \mathrm{~min}$ on the rod rotating at a speed of $25 \mathrm{rpm}$. On the following day, each test material, 1\% SCMC (untreated control) and 4 $\mathrm{mg} / \mathrm{kg}$ body weight diazepam (reference control), was administered orally to each mouse and its ability to remain on the rotating rod was assessed before and 30 min after the oral administration. The fall-off time (sec) from the rod was noted for each animal. 


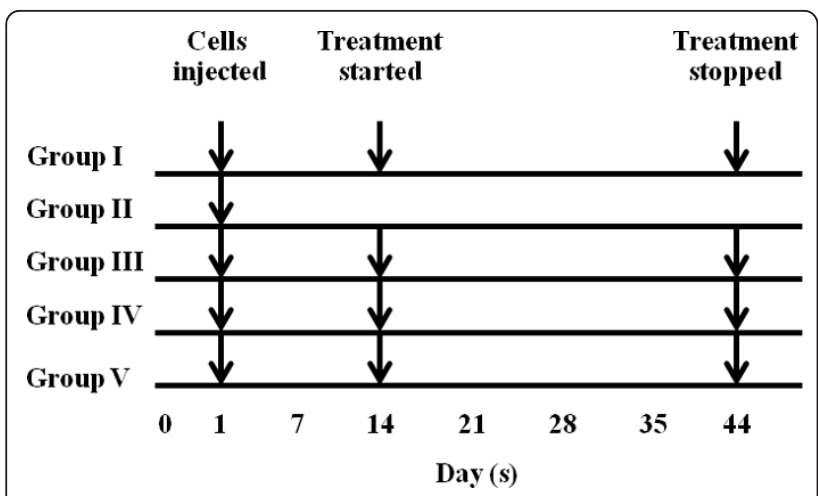

Figure 12 Schematic diagram representing treatment sequence for the evaluation of anticancer activity of CUR compound and plant extracts in CCA-xenografted nude mouse model. Cells injected $=$ subcutaneous injection of CL-6; Treatment started $=$ administration of treatment (CUR compound, each plant extract, vehicle or 5-FU); Treatment stopped = withdrawal of treatment (CUR compound, each plant extract, normal saline or 5-FU).

\section{Antihypertensive activity}

Rats were injected intraperitoneally with $0.1 \mathrm{ml}$ of adrenaline using a 1-ml disposable syringe for five consecutive days to induce hypertension [40]. Test materials, reference drug propanolol, and 1\% SCMC were given by oral administration for seven days. Blood pressure, heart rate, and mean arterial pressure were measured using CODA tail-cuff recorder (Kent Scientific, Torrington, CON, USA) machine in three steps, i.e., before treatment, one day after the last dose of adrenaline, and one day after the last dose of test materials or propanolol or $1 \%$ SCMC.

\section{Analgesic activity}

The analgesic activity of the test materials were evaluated using hot plate test [41] and writing test [42] for central and peripheral analgesic activity, respectively.

For the hot plate test, mice were placed to the beaker (on a hot plate) maintained at $55^{\circ} \mathrm{C} \pm 1^{\circ} \mathrm{C}$ in order to obtain their response to electrical heat-induced nociceptive stimulus. Latency of analgesic response characterized by manifestation of signs of acute discomfort, e.g., licking of a hind limb or jumping was observed. Starting at thirty minutes after oral administration of each test material or 1\% SCMC (untreated control), the analgesic response was measured at $15,30,45$, and 60 min period. For the reference control group, morphine sulfate at a dose of $5 \mathrm{mg} / \mathrm{kg}$ body weight was injected subcutaneously into each mouse and the analgesic response was measured. Only mice that remained on the rod during the 15-45 minutes were used for initial screening and the cut-off time of $15 \mathrm{sec}$ was used to evaluate analgesic activity of each test material.

For the assessment of writhing behavior, the test materials, the reference analgesic drug aspirin $(200 \mathrm{mg} / \mathrm{kg})$ or vehicle control (1\% SMC) were orally administered to all mice 30 min before the intraperitoneal injection of $0.6 \%$ acetic acid (10 mg/kg body weight). The number of writhings and stretchings were counted over a $20 \mathrm{~min}$ period.

\section{Anti-inflammatory activity}

Carrageenan-induced paw edema was used to investigate the anti-inflammatory activity of the test materials [43]. The initial right hind paw volume of the rats was measured using a plethysmometer (Ugo Basile, Comerio, $\mathrm{VA}$, Italy) and then $0.1 \mathrm{ml}$ of $1 \%(\mathrm{w} / \mathrm{v}) \lambda$-carrageenan was subcutaneously injected into the subplantar region of the right hind paw. The volume of the right hind paw was measured at $1,2,3,4$, and $5 \mathrm{hr}$ after carrageenan injection. Test materials, vehicle or reference drug indomethacin $(10 \mathrm{mg} / \mathrm{kg}$ body weight) were orally administered 30 min before carrageenan injection.

\section{Anti-ulcer activity}

The rats were fasted for 48 hours but were allowed free access to drinking water up to 2 hours before the experiment. Gastric ulcer was induced by orogastric intubation of absolute ethanol according to the method of De Pasquale et al. (1995) with modification [44]. The reference control group received an oral dose of $20 \mathrm{mg} /$ $\mathrm{kg}$ body weight omeprazole in 1\% SCMC (in volume of $5 \mathrm{ml} / \mathrm{kg}$ body weight). One hour after pre-treatment with test materials or omeprazole or $1 \%$ SCMC, all groups of rats were gavaged with absolute ethanol to induce gastric ulcer. The rats were euthanized by cervical dislocation 60 min later using diethyl ether and their stomachs were immediately excised. Ulcers found in the gastric mucosa appeared as elongated bands of hemorrhagic lesions parallel to the long axis of the stomach. Each specimen of gastric mucosa was thus examined for damage. The length $(\mathrm{mm})$ and width $(\mathrm{mm})$ of the ulcer on the gastric mucosa were measured under a microscope. The size of each ulcer lesion was measured and the sum of the areas of all lesions for each stomach was applied in the calculation of the ulcer area (UA), wherein the sum of small squares $\times 4 \times 1.8$ is equal to UA $\mathrm{mm}^{2}$ as described previously by Kauffman and Grossman (1978) with modification [45]. The inhibition percentage (I\%) was calculated as follow:

$$
(\mathrm{I} \%)=\left[\left(\mathrm{UA}_{\text {control }}-\mathrm{UA}_{\text {treated }}\right) / \mathrm{UA}_{\text {control }}\right] \times 100 \% .
$$

\section{Antipyretic activity}

The antipyretic activity of the test materials was evaluated using Brewer's yeast-induced pyrexia in rats [44]. Fever was induced in all rats by subcutaneous injection of $20 \mathrm{ml} / \mathrm{kg}$ boy weight of $20 \%$ aqueous suspension of Brewer's yeast in normal saline. All test materials, vehicle control (1\% SCMC), and reference drug paracetamol (150 mg/kg body weight) were administered orally 17 
hours after the induction of fever. Rectal temperature of each rat was recorded using thermal digital thermometer at $1,2,3,4,5$, and $6 \mathrm{hr}$ after the administration of the test materials, $1 \% \mathrm{SCMC}$, and reference drug.

\section{Statistical analysis}

All quantitative variables were presented as mean \pm SEM. Comparison of all quantitative variables between the groups treated with test materials or reference drugs with the untreated control group was performed using ANOVA, followed by post hoc scheffe test. Comparison of the paired quantitative variables with baseline data after treatment was performed by paired $t$-test. Statistical significance level was set at $\alpha=0.05$ for all tests.

\section{Acknowledgements}

The study was supported by the Commission for Higher Education, Ministry of Education of Thailand (RG) and the National Research University Project of Thailand (NRU), Office of Higher Education Commission of Thailand. Tullayakorn Plengsuriyakarn receives financial support for his Ph.D. program from the Commission for Higher Education, Ministry of Education of Thailand. We thank Associate Professor Dr. Adisak Wongkajornsilp, Department of Pharmacology, Faculty of Medicine (Siriraj Hospital), Mahidol University for the support of CL-6 cell line.

\section{Author details}

${ }^{1}$ Thailand Center of Excellence for Drug Discovery and Development (TCEDDD), Thammasat University, Pathumthani, Thailand. ${ }^{2}$ Department of Research, National Cancer Institute, Ministry of Public Health, Bangkok, Thailand. ${ }^{3}$ Applied Thai Traditional Medicine Center, Faculty of Medicine, Thammasat University, Pathumthani, Thailand. ${ }^{4}$ Thailand Center of Excellence for Drug Discovery and Development (TCEDDD), Thammasat University, 99 Moo 18 Paholyothin Rd., Klongluang, Pathumthani 12121, Thailand.

\section{Authors' contributions}

TP conducted all the experimental studies and data analysis. VE participated in animals' recruitment. $\mathrm{KN}, \mathrm{PP}, \mathrm{PK}$, and $\mathrm{VT}$ participated in the design of the study. Al prepared plant materials and crude ethanolic extracts. KN finalized the manuscript. All authors read and approved the final manuscript.

\section{Competing interests}

The authors declare that they have no competing interests.

Received: 6 January 2012 Accepted: 27 March 2012

Published: 27 March 2012

\section{References}

1. Hejna M, Pruckmayer M, Raderer M: The role of chemotherapy and radiation in the management of biliary cancer: a review of the literature. Eur J Cancer 1998, 34(7):977-986.

2. Gao PF, Watanabe K: Introduction of the World Health Organization project of the International Classification of Traditional Medicine. Zhong Xi Yi Jie He Xue Bao 2011, 9(11):1161-1164.

3. Mahavorasirikul W, Viyanant V, Chaijaroenkul W, Itharat A, Na-Bangchang K: Cytotoxic activity of Thai medicinal plants against human cholangiocarcinoma, laryngeal and hepatocarcinoma cells in vitro. BMC Complement Altern Med 2010, 10:55.

4. Lee E, Surh YJ: Induction of apoptosis in $\mathrm{HL}-60$ cells by pungent vanilloids, [6]-gingerol and [6]-paradol. Cancer Lett 1998, 134(2):163-168.

5. Tatsuta M, lishi H: Effect of treatment with liu-jun-zi-tang (TJ-43) on gastric emptying and gastrointestinal symptoms in dyspeptic patients. Aliment Pharmacol Ther 1993, 7(4):459-462.

6. Patra A, Ghosh A: Amides of Piper chaba. Phytochemistry 1974, 13(12):2889-2890.
7. Chayamarit K: In Thai medicinal plants. Volume 5. Bangkok: Department of Forestry; 1995.

8. Kubo M, Nogami M, Nishimura M, Moriura T, Arichi S: Origins, processing, and qualities of crude drugs (1). Preventive effects of a Chinese crude drug, Zhu, on experimental stomach ulcer and its pharmacological evaluation. 1. Yakugaku Zasshi 1983, 103(4):442-448.

9. Resch M, Heilmann J, Steigel A, Bauer R: Further phenols and polyacetylenes from the rhizomes of Atractylodes lancea and their antiinflammatory activity. Planta Med 2001, 67(5):437-442.

10. Plengsuriyakarn T, Viyanant V, Eursitthichai V, Tesana S, Chaijaroenkul W, Itharat A, Na-Bangchang K: Study on cytotoxicity, toxicity, and anticancer activity of Zingiber officinale Roscoe against colangiocarcinoma. Phytomedicine (manuscript in press)

11. Shukla $Y$, Singh M: Cancer preventive properties of ginger: a brief review. Food Chem Toxicol 2007, 45(5):683-690.

12. Grzanna R, Lindmark L, Frondoza CG: Ginger - an herbal medicinal product with broad anti-inflammatory actions. J Med Food 2005, 8(2):125-132.

13. al-Yahya MA, Rafatullah S, Mossa JS, Ageel AM, Parmar NS, Tariq M: Gastroprotective activity of ginger zingiber officinale rosc., in albino rats. Am J Chin Med 1989, 17(1-2):51-56.

14. Ali BH, Blunden G: Pharmacological and toxicological properties of Nigella sativa. Phytother Res 2003, 17(4):299-305.

15. Cao W, Li XQ, Wang X, Li T, Chen X, Liu SB, Mei QB: Characterizations and anti-tumor activities of three acidic polysaccharides from Angelica sinensis (Oliv.) Diels. Int J Biol Macromol 2010, 46(1):115-122.

16. Zheng GQ, Kenney PM, Lam LK: Anethofuran, carvone, and limonene: potential cancer chemopreventive agents from dill weed oil and caraway oil. Planta Med 1992, 58(4):338-341.

17. Mohamad RH, El-Bastawesy AM, Abdel-Monem MG, Noor AM, AlMehdar HA, Sharawy SM, El-Merzabani MM: Antioxidant and anticarcinogenic effects of methanolic extract and volatile oil of fennel seeds (Foeniculum vulgare). J Med Food 2011, 14(9):986-1001.

18. Oh H, Lee HS, Kim T, Chai KY, Chung HT, Kwon TO, Jun JY, Jeong OS, Kim YC, Yun YG: Furocoumarins from Angelica dahurica with hepatoprotective activity on tacrine-induced cytotoxicity in Hep G2 cells. Planta Med 2002, 68(5):463-464

19. Ngo NT, Nguyen VT, Vo HV, Vang O, Duus F, Ho TD, Pham HD, Nguyen LH: Cytotoxic coumarins from the bark of Mammea siamensis. Chem Pharm Bull (Tokyo) 2010, 58(11):1487-1491.

20. Chirathaworn C, Kongcharoensuntorn W, Dechdoungchan T, Lowanitchapat A, Sa-nguanmoo P, Poovorawan Y: Myristica fragrans Houtt. methanolic extract induces apoptosis in a human leukemia cell line through SIRT1 mRNA downregulation. J Med Assoc Thai 2007, 90(11):2422-2428.

21. Banerjee $S$, Das S: Anticarcinogenic effects of an aqueous infusion of cloves on skin carcinogenesis. Asian Pac J Cancer Prev 2005, 6(3):304-308.

22. Rooney S, Ryan MF: Effects of alpha-hederin and thymoquinone, constituents of Nigella sativa, on human cancer cell lines. Anticancer Res 2005, 25(3B):2199-2204.

23. Shoieb AM, Elgayyar M, Dudrick PS, Bell JL, Tithof PK: In vitro inhibition of growth and induction of apoptosis in cancer cell lines by thymoquinone. Int J Oncol 2003, 22(1):107-113.

24. Gali-Muhtasib H, Diab-Assaf M, Boltze C, Al-Hmaira J, Hartig R, Roessner A, Schneider-Stock R: Thymoquinone extracted from black seed triggers apoptotic cell death in human colorectal cancer cells via a p53dependent mechanism. Int J Oncol 2004, 25(4):857-866.

25. Roepke M, Diestel A, Bajbouj K, Walluscheck D, Schonfeld P, Roessner A, Schneider-Stock R, Gali-Muhtasib H: Lack of p53 augments thymoquinone-induced apoptosis and caspase activation in human osteosarcoma cells. Cancer Biol Ther 2007, 6(2):160-169.

26. Wilson-Simpson F, Vance S, Benghuzzi H: Physiological responses of ES-2 ovarian cell line following administration of epigallocatechin-3-gallate (EGCG), thymoquinone (TQ), and selenium (SE). Biomed Sci Instrum 2007, 43:378-383.

27. Sethi G, Ahn KS, Aggarwal BB: Targeting nuclear factor-kappa B activation pathway by thymoquinone: role in suppression of antiapoptotic gene products and enhancement of apoptosis. Mol Cancer Res 2008, 6(6):1059-1070. 
28. Ozaki Y, Soedigdo S, Wattimena YR, Suganda AG: Antiinflammatory effect of mace, aril of Myristica fragrans Houtt., and its active principles. Jpn J Pharmacol 1989, 49(2):155-163.

29. Houghton PJ, Zarka R, De las Heras B, Hoult JR: Fixed oil of Nigella sativa and derived thymoquinone inhibit eicosanoid generation in leukocytes and membrane lipid peroxidation. Planta Med 1995, 61(1):33-36.

30. Chao WW, Hong YH, Chen ML, Lin BF: Inhibitory effects of Angelica sinensis ethyl acetate extract and major compounds on NF-kappaB trans-activation activity and LPS-induced inflammation. J Ethnopharmacol 2010, 129(2):244-249.

31. Likhitwitayawuid K, Sawasdee K, Kirtikara K: Flavonoids and stilbenoids with COX-1 and COX-2 inhibitory activity from Dracaena loureiri. Planta Med 2002, 68(9):841-843.

32. Kim CM, Heo MY, Kim HP, Sin KS, Pachaly P: Pharmacological activities of water extracts of Umbelliferae plants. Arch Pharm Res 1991, 14(1):87-92.

33. Abdel-Fattah AM, Matsumoto K, Watanabe $\mathrm{H}$ : Antinociceptive effects of Nigella sativa oil and its major component, thymoquinone, in mice. Eur J Pharmacol 2000, 400(1):89-97.

34. Zhu HL, Ji JL, Huang XF: Curcumin and its formulations: potential anticancer agents. Anticancer Agents Med Chem 2011.

35. John S, Nikhil S, Yaswanth J, Bhaskar A, Amit A, Sudha S: Analgesic property of different extracts of Curcuma longa (Linn): an experimental study in animals. J Nat Remed 2009, 9(1):116-120.

36. Tuorkey M, Karolin K: Anti-ulcer activity of curcumin on experimental gastric ulcer in rats and its effect on oxidative stress/antioxidant, IL-6 and enzyme activities. Biomed Environ Sci 2009, 22(6):488-495.

37. OECD: Acute oral toxicity, guideline 420 , the OECD guideline for testing of chemical. 2001.

38. Chaimuangraj S, Thamavit W, Tsuda H, Moore MA: Experimental investigation of opisthorchiasis-associated cholangiocarcinoma induction in the Syrian hamster - pointers for control of the human disease. Asian Pac J Cancer Prev 2003, 4(2):87-93.

39. Dunham NW, Miya TS: A note on a simple apparatus for detecting neurological deficit in rats and mice. J Am Pharm Assoc Am Pharm Assoc (Baltim) 1957, 46(3):208-209.

40. James O, Friday EA, Unekwuojo EG: Antihypertensive Effect of Methanol Extract of Napoleona imperialis ( $p$. beauv) in Adrenaline Induced Hypertensive Albino Rats. Inter J Biochem Res Rev 2011, 1(2):47-57.

41. Woolfe G, MacDonald AD: The evaluation of the analgesic action of pethidine hydrochloride (Demerol). Journal of Pharmacology and Experimental Therapeutics 1944, 80(3):300-307.

42. Koster R, Anderson M, De Beer EJ: Acetic acid for analgesic screening. Fed Proc 1959, 18:412-416.

43. Winter CA, Risley EA, Nuss GW: Carrageenin-induced edema in hind paw of the rat as an assay for antiiflammatory drugs. Proc Soc Exp Biol Med 1962, 111:544-547.

44. De Pasquale R, Germano MP, Keita A, Sanogo R, lauk L: Antiulcer activity of Pteleopsis suberosa. J Ethnopharmacol 1995, 47(1):55-58.

45. Kauffman GL Jr, Grossman Ml: Prostaglandin and cimetidine inhibit the formation of ulcers produced by parenteral salicylates. Gastroenterology 1978, 75(6):1099-1102.

\section{Pre-publication history}

The pre-publication history for this paper can be accessed here: http://www.biomedcentral.com/1472-6882/12/23/prepub

doi:10.1186/1472-6882-12-23

Cite this article as: Plengsuriyakarn et al: Anticancer activities against cholangiocarcinoma, toxicity and pharmacological activities of Tha medicinal plants in animal models. BMC Complementary and Alternative Medicine 2012 12:23.

\section{Submit your next manuscript to BioMed Central and take full advantage of:}

- Convenient online submission

- Thorough peer review

- No space constraints or color figure charges

- Immediate publication on acceptance

- Inclusion in PubMed, CAS, Scopus and Google Scholar

- Research which is freely available for redistribution

Submit your manuscript at www.biomedcentral.com/submit
Biomed Central 